\title{
Evaluaciones agroecológicas de dos híbridos de brócoli (Brassica oleracea) en el municipio de Sibaté, Cundinamarca
}

Daniel Vega C.

Recibido el 8 de octubre de 2009. Aprobado el 9 de marzo de 2010

\begin{abstract}
Resumen
El brócoli es una hortaliza, fuente de vitaminas, ácido fólico, niacina y provitamina a (Beta - caroteno), vitaminas B1 y E. En su contenido mineral sobresale el potasio. Además, posee una serie de elementos fotoquímicos cuya potencial utilidad en la prevención de diversos tipos de enfermedades justifica el creciente interés en su consumo. El presente artículo compila un trabajo que se desarrolló a partir de un Diseño de Bloques completamente aleatorios con el objeto de valorar dos híbridos comerciales de Brócoli (Brassica olaracea), con el fin de evaluar parámetros de adaptabilidad y especificaciones comerciales de calidad para la misma. Los tratamientos evaluados fueron: T1; Híbrido Marathón. T2; Híbrido Legacy. A la cosecha, se procedió a evaluar los parámetros exigidos por el departamento comercial de Uniminuto, los cuales están estrechamente relacionados con aspectos cuantitativos en el sistema productivo del Brócoli. A modo de conclusión general, se puede decir, que en consonancia con los parámetros comerciales (Ciclo vegetativo, peso en fresco, radio y turgencia de pella) los dos híbridos evaluados no presentan diferencia significativa, por consiguiente, cualquiera de los dos híbridos que se implemente comercialmente, darán resultados muy similares. Siendo única la diferencia que radica en el porcentaje de agua que contiene cada uno de estos híbridos, siendo mayor para el hibrido Legacy, comparado frente al híbrido Marathón, lo que sugiere un mayor contenido de minerales y menor tiempo en el proceso de cocción para el híbrido Marathón. Este último, arrojó mayores contenidos en materia seca.
\end{abstract}

\section{Palabras clave}

Agricultura orgánica, híbridos, Brassica olarace. 


\begin{abstract}
Broccoli is a vegetable, source of vitamins; it contains folic acid, niacin, beta-carotene, vitamins B1 and E. It possesses a series of photochemical elements, which usefulness potential prevent certain types of cancer and other diseases. This is why there has been a significant increase in consumption of broccoli, in recently years. The present article compiles a work that was developed from a randomized block design test in order to evaluate two commercial hybrids varieties of broccoli, and to analyze parameters of adaptability and quality and commercial specifications for the same one. The two treatments evaluated were the following ones: T1; Hybrid Marathon. T2; Hybrid Legacy. At the time of harvest, we evaluated parameters required by the Uniminuto's commercial department, which are closely related to quantitative aspects in the production system of broccoli. As a general conclusion, one can say that in agreement with the commercial setting (the vegetative cycle, fresh weight, radio and swelling of the head of broccoli) of both hybrids varieties evaluated do not show significant differences. Therefore either of the two hybrids could be implemented commercially, and will have similar results. The difference arises in the percentage of water contained in these two hybrids, Legacy has higher water content, and in comparison Marathon has lower water content. This suggests Marathon has a higher mineral content, and it takes less time in the process of boiling, which also suggests it has a higher content in dry matter.
\end{abstract}

Keywords

Organic agriculture, Hybrids, Brassica olaracea

\section{Introducción}

Las crucíferas son un importante grupo de especies hortícolas, tanto por el área sembrada como por el valor de su producción. Las crucíferas de mayor importancia económica son brócoli, coliflor, repollo, col china, col de brúcelas y col. El contenido nutricional de estas especies hortícolas resulta variable, dependiendo principalmente de las condiciones ambientales donde se desarrolla la planta, la edad de la misma, las propiedades del cultivar, y el método de conservación, procesamiento y preparación (Jaramillo, J. \& Díaz, C. 2006)

El brócoli es fuente de vitaminas, ácido fólico y niacina y provitamina a (Beta - caroteno), vitaminas Bl y E. En su contenido mineral sobresalen el potasio y cantidades significativas de calcio, magnesio, zinc, yodo y hierro. Posee una serie de elementos fotoquímicos cuyos potenciales efectos en la prevención de diversos tipos de cánceres y otras enfermedades justifica el creciente interés en su consumo (Plan Hortícola nacional, asohofrucol, Colombia, 2009)

En el cultivo de Brócoli, juega un papel primordial el material vegetal, existiendo una amplia oferta de material híbrido catalogado por diferentes empresas productoras de semilla. Una correcta elección de los cultivares permite diseñar calendarios de producción, que puedan dar lugar a recolecciones durante al menos 10 meses del año, ubicando cada variedad en función de la localización, fechas de siembra y ciclo de cultivo, con el objeto de obtener un producto de máxima calidad, de manera continua (Maroto, J., Pomares, F. \& Baixauli, C. 2007)

Las inflorescencias deben ser de forma regular, sin deformaciones ni huecos en el tallo, estar suficien- temente compactadas, con botones florales uniformemente cerrados, de pequeño calibre y sin mostrar amarilleos, enmarronecimientos, bracteación (Maroto, J. Pomares, F. \& Baixauli, C. 2007)

Según las estadísticas agropecuarias del municipio de Sibaté, Cundinamarca, la producción de brócoli no es representativa en la zona, predominan los cultivos de papa, fresa, arveja, así como el cultivo de pastos para explotación ganadera. (Secretaria de agricultura de Sibaté-2009)

Las condiciones climatológicas de la zona donde se establece el cultivo tales como la altura sobre el nivel del mar, horas luz, temperatura, pluviosidad, son parámetros para establecer el desarrollo y la productividad del cultivo, así como la necesidad de implementar riego adicional y sus jornadas de aplicación (Guía ambiental para el subsector hortofrutícola, asohofrucol, 2002) A su vez, La duración del ciclo vegetativo y la época en que maduran las hortalizas se afecta por la extensión que el periodo de luz solar tenga durante el crecimiento (Lozano, M. 1987)

La evaluación agroecológica de híbridos en el sistema productivo de Brócoli, permitirá implementar, gracias a la respuesta de adaptabilidad a las condiciones agroecológicas de la zona, materiales que cumplan con parámetros de calidad, exigidos por los diferentes mercados de esta hortaliza.

\section{Materiales y métodos}

Ubicación: Este trabajo se realizó en la finca Agroecológica de la Corporación Universitaria Minuto de Dios (UNIMINUTO) localizada en la vereda San Miguel Municipio de Sibaté Cundinamarca, la cual presenta una temperatura promedio de $12{ }^{\circ} \mathrm{C}$ y se localiza a una altura de $2.761 \mathrm{msnm}$. 
Material de propagación: Se trabajó con plántulas de Brócoli, híbrido Legacy, provenientes de la empresa RIOPLANT LTDA y con plántulas de Brócoli, híbrido Marathón, provenientes de la empresa EUROFRESH.

Preparación de suelos: Se realizó con tracción animal y con la ayuda de herramientas livianas, con el objeto de evitar una mecanización excesiva del suelo.

Siembra: Esta actividad, se realizó en camas de $1,20 \mathrm{~m}$ de ancho, utilizando una distancia de siembra entra plántulas de 0,40 m y una distancia entre calles de $0,50 \mathrm{~m}$

Fertilización: Al momento del trasplante, se aplicó $200 \mathrm{~g} /$ sitio de siembra de abob (abono orgánico deshidratado) y $100 \mathrm{~g}$ al momento del aporque. Asimismo, al momento de la siembra se inocularon los sitios de siembra con:

EM 10\%: Microorganismos eficaces. (Bacterias Fototróficas, Bacterias Ácido Lácticas y Levaduras)

Fosforiz 5\%: Pseudomonas sp. (Bacterias solubilizadoras de fósforo)

Azobac 5\%: Azotobacter sp. y Azospirillum sp. (Bacterias solubilizadoras de Nitrógeno)

Súper magro 10\%: Bioprepardo con elementos mayores y menores.

Diseño experimental: Se utilizó un diseño de bloques completamente al azar, con 4 bloques, 2 tratamientos y 4 repeticiones.

Área experimental: Se delimitó un área para este experimento de $126 \mathrm{~m} 2$. (20 m de largo, por 6,3 m de ancho)

Bloques: El área experimental se dividió en cuatro bloques, cada uno con un área de $31.5 \mathrm{~m} 2$. En cada bloque se realizó el respectivo proceso aleatorio con los distintos tratamientos.

Tratamientos: Se definieron 2 tipos de tratamientos por cada bloque.

T1: Híbrido Legacy. T2: Híbrido Marathón

Proceso Aleatorio: Ver figura 1

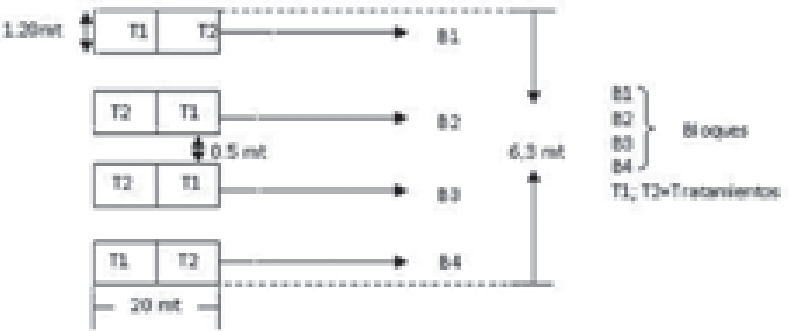

Figura 1. Distribución del Diseño experimental en campo. Fuente: El autor
Repeticiones: Se establecieron cuatro repeticiones para cada uno de los tratamientos.

Unidad observacional: Se determinó una unidad de observación de 3,6 m2.

Población de referencia: Se tomaron 10 plantas de la unidad observacional, es decir el 12,5\% del total de plantas sembradas.

Análisis estadístico: Para el presente estudio, el análisis de datos se llevó a cabo con el programa Statgraphics $($. Las variables analizadas en Brócoli fueron: Peso en fresco, peso seco, materia seca, diámetro y turgencia de pella, parámetros cuantitativos al momento de la cosecha. Además, se evaluó ciclo vegetativo, inducción floral, y formación de pella para la cosecha. Para cada una de las variables mencionadas, se realizó un análisis de varianza y un tesł (prueba) de comparación de medias LSD (Diferencia mínima significativa).

Riegos: Para esta labor se utilizó un sistema de riego por aspersión

Control de plagas: El control de las plagas se realizó mediante técnicas sostenibles, amigables con el medio ambiente, haciendo énfasis en control biológico y buenas prácticas agrícolas; aprobadas según la resolución 0187 de 2006 por el Ministerio de Agricultura y Desarrollo Rural.

Prácticas culturales: Se efectuó un aporque, a los 49 días de trasplantado el material vegetal al campo.

Cosecha: En el estudio en mención, se cosechó la población citada, utilizando para esto cuchillos de sierra, tipo tramontina, en acero inoxidable.

Una vez extraída la pella, se procedió a realizar las respectivas mediciones a evaluar de la siguiente forma.

Precocidad de los materiales: Determinado por la duración del ciclo vegetativo desde el momento del trasplante a campo, hasta el momento de la cosecha.

Peso en fresco de pella al momento de la cosecha: Para lo cual se utilizó gramera marca adventurer ohaus Max Cap 1500 gr, readability 0,01 gr.

Peso en seco de pella: Las muestras se llevaron a una temperatura de $70^{\circ} \mathrm{C}$ durante 72 horas, en una mufla tipo Binder $0-250{ }^{\circ} \mathrm{C}$.

Porcentaje materia seca: Dado por:

MS: Materia seca

Ps: Peso Seco

Pf: Peso fresco
$\%$ MUS $=\left(\frac{P s}{P f}\right) * 100$ 
Diámetro de pella a la cosecha: Calibrador al momento de la cosecha.

Turgencia de pella al momento de la cosecha: Se calculó con penetrómetro de frutas y hortalizas referencia Wagner, force dial FDK 160, 10lbf x 2 ozf.

\section{Resultados y discusión Peso en fresco}

En cuanto a esta variable, se observa que NO existe diferencia estadísticamente significativa en los dos tratamientos: Híbrido Legacy (Media: 125,2 gramos) e Híbrido Marathón (Media: 126,8 gramos) ver figura 2; Lo que sugiere, que ambos híbridos muestran rendimientos similares a las condiciones agroecológicas de la zona.

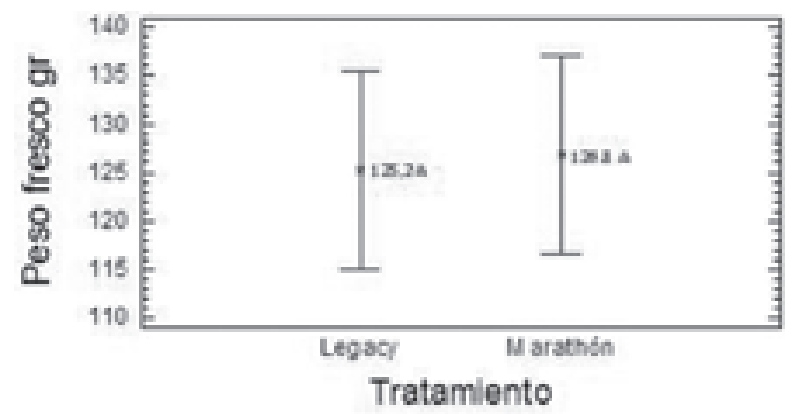

Figura 2. Diferencia mínima significativa para peso en fresco. Fuente: El autor

* Promedios con diferente letra, difieren significativamente con un $\mathrm{P} \leq 0,05$

\section{Peso en seco}

Se observó que existe diferencia estadísticamente significativa entre los dos híbridos de brócoli analizados, obteniendo un mayor peso en seco el tratamiento del híbrido Marathón (media: 12,82 g), comparado con el híbrido Legacy (media: 19,73 g), (figura 3) lo que indica un contenido mayor de agua para el híbrido Legacy.

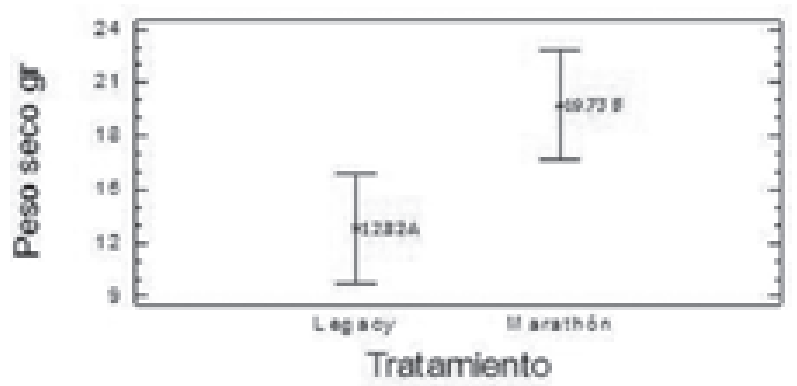

Figura 3. Diferencia mínima significativa para peso en seco. Fuente: El autor.

* Promedios con diferente letra, difieren significativamente con un $\mathrm{P} \leq \mathrm{0,05}$ Dureza
Se puede observar (figura 4) que NO existe diferencia estadísticamente significativa en la variable turgencia de la pella, en los dos híbridos evaluados, dando como resultado, cabezas compactas, firmes al tacto y de aceptación comercial.

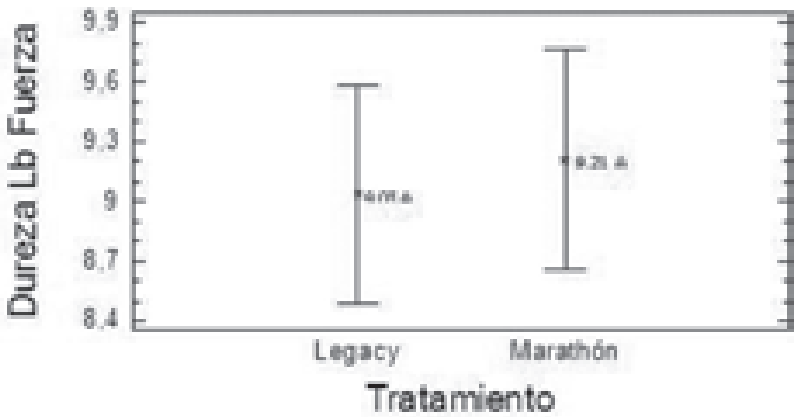

Figura 4. Diferencia mínima significativa para dureza. Fuente: El autor

Promedios con diferente letra, difieren significativamente con un $\mathrm{P} \leq 0,05$

\section{Diámetro}

A pesar que el híbrido Legacy presentó un mayor diámetro de cabeza, (figura 5) NO existe diferencia estadísticamente significativa entre los dos tratamientos evaluados, lo que da como resultado, cabezas de diámetro similar en los híbridos evaluados. (Legacy y Marathón)

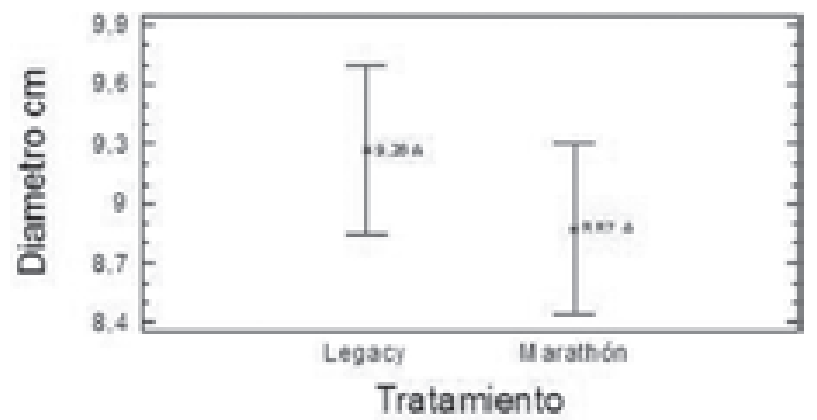

Figura 5. Diferencia mínima significativa para diámetro. Fuente: El autor

* Promedios con diferente letra, difieren significativamente con un $\mathrm{P} \leq 0,05$

\section{Materia seca}

Se observa que existe diferencia estadísticamente significativa entre los dos híbridos, dando como resultado una mayor acumulación de materia seca para el híbrido Marathón (media: 15,50 gramos frente al híbrido Legacy (media: 10,24 gramos). (Figura 6). El porcentaje de materia seca, está estrechamente relacionado con el contenido nutricional del brócoli, lo que sugiere una mayor calidad alimenticia para el híbrido Marathón frente al híbrido Legacy. 


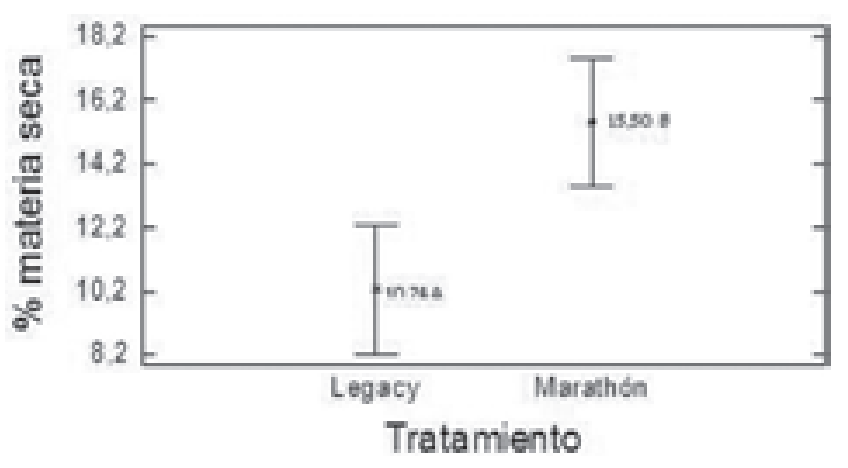

Figura 6. Diferencia mínima significativa para \% materia seca. Fuente: El autor

* Promedios con diferente letra, difieren significativamente con un $\mathrm{P} \leq 0,05$

\section{Resultados referente a la variable ciclo productivo}

Ambos materiales evaluados en el estudio, demostraron tener un ciclo similar, y no presentaron diferencia estadísticamente significativa (figuras 7 y 8 ).

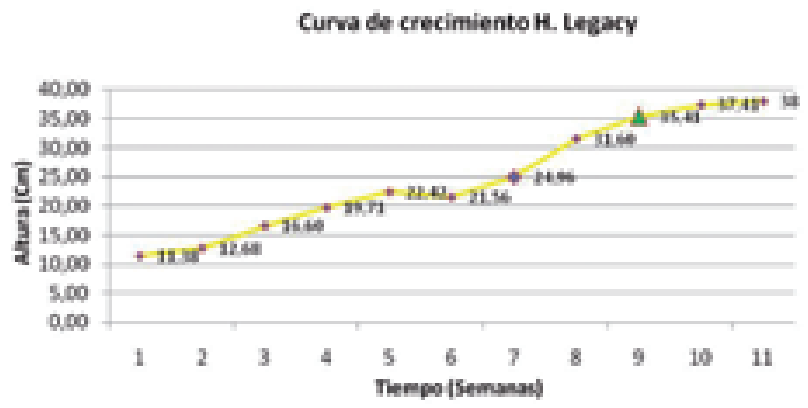

Figura 7. Promedio de Crecimiento híbrido Legacy. Fuente: El autor

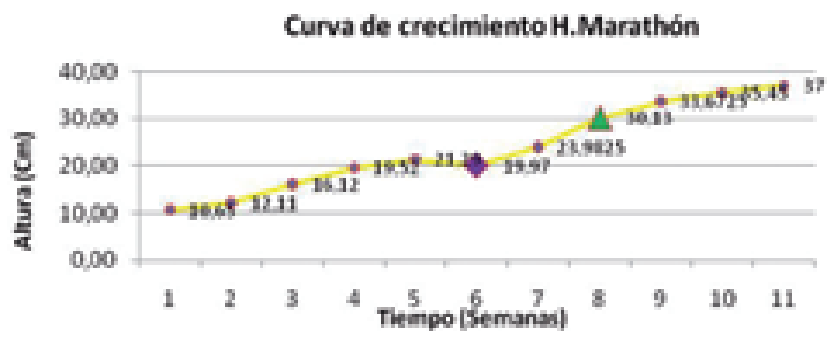

Figura 8. Promedio de Crecimiento híbrido Legacy. Fuente: El autor

Los híbridos Legacy y Marathón presentaron frente a las condiciones agroecológicas de la zona, similitud referente a ciclo vegetativo, formación floral, formación de pella y cosecha.

\section{Conclusiones}

- Frente a la variable peso en fresco, no existe diferencia estadísticamente significativa, pero se obtuvo un mayor peso de cabeza de brócoli con el híbrido Marathón (Media: 126,8 g), referente al híbrido Legacy (Media: 125,2 g).
- El híbrido Marathón obtuvo un 35\% más de peso seco, existiendo diferencia mínima significativa frente al híbrido Legacy, según las medias observadas (Marathón media: 12,82 g) (Legacy media: 19,73 g).

- Frente a la variable turgencia de pella, se puede concluir que no existe diferencia estadísticamente significativa entre los tratamientos, dando como resultado cabezas de brócoli de granos apretados, firmes y de buena aceptación para el mercado en los dos híbridos evaluados (Marathón y Legacy).

- Se puede concluir referente a la variable diámetro de cabeza de brócoli, que no existe diferencia estadísticamente significativa entre el híbrido Marathón y Legacy, y cualquiera de los dos híbridos presenta cabezas regulares de buen tamaño y de óptima calidad para cumplir las exigencias del mercado.

- Se observó que el híbrido Marathón comparado al híbrido Legacy tiene la capacidad de acumular mayor contenido de materia seca, lo que se ve reflejado en una mayor calidad de producto debido a los componentes sólidos, principalmente minerales, que se almacenan en la fracción de la materia seca.

- No existe diferencia estadísticamente significativa en las etapas del desarrollo productivo en los dos híbridos evaluados en el presente estudio. El desarrollo vegetativo en ambos híbridos se prolonga hasta la octava semana después del trasplante; la aparición de botón floral se dio inicio en la semana número nueve; y la cosecha se llevó a cabo en la semana doce.

- Como conclusión general, se puede decir que en parámetros comerciales, (Ciclo vegetativo, peso en fresco, radio y turgencia de pella) los dos híbridos evaluados no presentan diferencia significativa, por consiguiente cualquiera de los dos híbridos que se implementen comercialmente darán resultados muy similares. La diferencia radica en los porcentajes de agua que contiene cada uno de estos híbridos, siendo mayor para Legacy, comparado frente al híbrido Marathón, lo que sugiere un mayor contenido de minerales y menor tiempo en la cocción para el híbrido Marathón, el cual arrojó los mayores contenidos de materia seca.

\section{Referencias}

[1] Corporación Colombia Internacional (CCI) (s.f.), Plan Hortícola Nacional, disponible en:http://www. asohofrucol.com.co/archivos/biblioteca/biblioteca_ 28_PHN.pdf, recuperado: 12 de abril de 2010. 
[2] Herrera, H. et al. (2006), Guía para la Implementación de Buenas Prácticas Agrícolas en Lechuga y Brócoli, Tibaitatá, CORPOICA.

[3] Jaramillo, J. \& Díaz, C. (2006), El cultivo de Las cruciferas, brócoli, coliflor, repollo, col china. Tibaitatá, CORPOICA.

[4] Lopera, M. et al. (2009), Guía ambiental hortofrutícola de Colombia, Bogotá, D.C. Colombia, Ministerio de Ambiente, Vivienda y Desarrollo Territorial, Asociación Hortifrutícola de Colombia - ASOHORCOL.

[5] Lozano, M. Manual práctico de hortalizas (1987). Edición número 7, temas de orientación agropecuaria, España, pp. 18.

[6] Maroto, J. Pomares, F. \& Baixauli, C. (2007), El cultivo de la Coliflor y el Brócoli, Madrid, Ediciones Mundi-Prensa.

Daniel Vega C. Ingeniero en agroecología de la Corporación Universitaria Minuto de Dios (UNIMINUTO). En la actualidad es docente de tiempo completo del Programa de Ingeniería Agroecológica de la Corporación Universitaria Minuto de Dios (UNIMINUTO). agroecologiavega@gmail.com 